\title{
WestVirginiaUniversity
}

THE RESEARCH REPOSITORY @ WVU

Graduate Theses, Dissertations, and Problem Reports

2011

\section{The Sharing of and Reactions to Positive Events in Romantic Relationships}

Jennifer N. Morey

West Virginia University

Follow this and additional works at: https://researchrepository.wvu.edu/etd

\section{Recommended Citation}

Morey, Jennifer N., "The Sharing of and Reactions to Positive Events in Romantic Relationships" (2011). Graduate Theses, Dissertations, and Problem Reports. 3289.

https://researchrepository.wvu.edu/etd/3289

This Thesis is protected by copyright and/or related rights. It has been brought to you by the The Research Repository @ WVU with permission from the rights-holder(s). You are free to use this Thesis in any way that is permitted by the copyright and related rights legislation that applies to your use. For other uses you must obtain permission from the rights-holder(s) directly, unless additional rights are indicated by a Creative Commons license in the record and/ or on the work itself. This Thesis has been accepted for inclusion in WVU Graduate Theses, Dissertations, and Problem Reports collection by an authorized administrator of The Research Repository @ WVU. For more information, please contact researchrepository@mail.wvu.edu. 
The Sharing of and Reactions to Positive Events in Romantic Relationships

\author{
Jennifer N. Morey
}

\begin{abstract}
Thesis submitted to the Eberly College of Arts and Sciences

at West Virginia University in partial fulfillment of the requirements

for the degree of
\end{abstract}

\author{
Master of Science \\ in \\ Life-Span Developmental Psychology
}

\author{
Amy L. Gentzler, Ph.D., Chair \\ Tracy Morris, Ph.D. \\ JoNell Strough, Ph.D. \\ Department of Psychology \\ Morgantown, West Virginia \\ 2011
}

Keywords: Positive events, romantic relationships, attachment, capitalizing 


\begin{abstract}
The Sharing of and Reactions to Positive Events in Romantic Relationships
\end{abstract}

\title{
Jennifer N. Morey
}

This study investigated positive event sharing (i.e., capitalization) in romantic relationships as well as partners' responses to participants' positive event sharing, and examined how each relates to attachment style and relationship satisfaction. Participants (aged 18-25, with 89 men and 95 women within 92 couples) completed online daily logs of positive events that occurred over a one week period, whether or not they shared those events with their romantic partners, and their reaction and their partners' reaction to those events. They also completed measures of attachment, their partner's general reactions to their positive event sharing, and support-seeking in a lab visit. Romantic partners reported on an online survey about how they responded to their partner's disclosure and also completed measures of attachment style and relationship satisfaction. Results indicated that perceived partner responses predicted participant's relationship satisfaction, even when controlling for support seeking. Participants who were low in attachment anxiety shared the most positive events over the course of the study, and also reported that partners responded in a more positive manner to their positive event sharing. Partner's self-reported responses were related to their gender and attachment, with women and those low in attachment anxiety and avoidance reporting more positive responses. Finally, participants' attachment avoidance was somewhat related to a higher discrepancy between participant and partner report for the same event. Results provide further support for the moderating role of attachment in capitalization (shown with avoidance; Hicks \& Diamond, 2008), and also provide new evidence to suggest that attachment plays a crucial role in how partners actually respond when hearing a participants' positive event disclosure. 
TABLE OF CONTENTS

Table of Contents $\quad$ i

Abstract ii

Table of Contents iii

LIST OF TABLES iv

INTRODUCTION 1

$\begin{array}{ll}\text { METHODS } & 14\end{array}$

$\begin{array}{ll}\text { RESULTS } & 25\end{array}$

DISCUSSION 34

$\begin{array}{ll}\text { REFERENCES } & 48\end{array}$ 


\section{LIST OF TABLES}

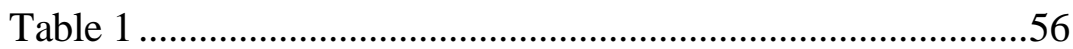

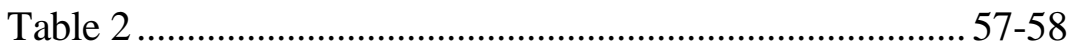

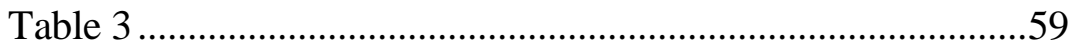




\section{The Sharing of and Reactions to Positive Events in Romantic Relationships}

When people experience positive events in their daily lives, they often share these experiences with other people, especially those closest to them such as their romantic partners. However, most empirical research on romantic relationships to date has focused on negative events and emotions as demonstrated by the large stress and coping literature (e.g., Lazarus \& Folkman, 1984). Sharing positive life experiences with other people has been shown to increase positive feelings and subjective well-being for the discloser (Langston, 1994), but only if their partner's reaction is viewed as supportive (Gable, Gonzaga, \& Strachman, 2006). Many personality characteristics may affect both how an individual responds to their romantic partner's attempts at sharing positive events and how they perceive their partner's responses to their own positive event disclosures. One major individual characteristic that affects many aspects of behavior in romantic relationships is attachment style. Therefore, the goal of this study was to better understand how people respond to their own and their partner's positive life events and to investigate whether these were predictable from attachment style or had an impact on relationship satisfaction.

\section{Capitalization}

Capitalization, or positive event sharing, is "the process of informing another person about the occurrence of a personal positive event and thereby deriving additional benefit from it" (Gable, Impett, Reis, \& Asher, 2004, pp. 228; Langston, 1994). The sharing of personal positive events with a romantic partner has important causal implications for personal health and relationship well-being (Gable et al., 2006; Gottman, 1982; Reis et al., 2010), even beyond those benefits associated with the positive event itself (Langston, 1994). For example, Hicks and Diamond (2008) found that participants were happiest on days where they shared their positive 
events with their romantic partners and on days where their partners shared their positive events with them. Thus, one expectation in the current study was that individuals who reported sharing a greater number of positive events with romantic partners would also report greater relationship satisfaction.

According to the broaden-and-build theory, the sharing of positive emotions and life events with others can both broaden and build an individual's skills and resources (Fredrickson, 1998; Fredrickson, 2001; Fredrickson \& Joiner, 2002). Specifically, experiencing positive emotions can widen people's ability to think and pay attention, increase their resilience and personal resources, decrease negative arousal, and generally lead to enhanced well-being (Fredrickson, 2006; Fredrickson \& Branigan, 2005). Positive emotions can also have an important buffering effect on life stresses or other negative events (Tugade \& Fredrickson, 2004; Tugade, Fredrickson, \& Barrett, 2004). In addition, in his daily diary studies Langston (1994) found that people often do not express or celebrate their positive life events, but doing so can have significant effects for how one feels about the positive event by increasing their positive affect beyond that associated with the initial event. He found that sharing with others increased positive affect, but so did other strategies such as "marking" the event or trying to make the event more memorable. Therefore, sharing positive life events with others is one important way by which individuals can build their available social resources and achieve the benefits associated with positive affect (Gable et al., 2004; Gable et al., 2006; Reis et al., 2010).

Research conducted by Gottman and his colleagues on romantic couples demonstrates how overall positive affect can be important for romantic relationships (Gottman \& Levenson, 1992; Levenson, Carstensen, \& Gottman, 1994). Generally, the results of their work indicate that overall positive and negative affect as well as the ratio of positive-to-negative emotional 
expressions observed during conflict discussions can predict both marital satisfaction and stability (Gottman, Coan, Carrere, \& Swanson, 1998; Gottman \& Levenson, 1992; 1999; Levenson et al., 1994; Pasupathi, Carstensen, Levenson, \& Gottman, 1999). Specifically, couples in strong relationships share positive interactions more often when engaging in conflict discussions, and these interactions provide them with an opportunity to decrease conflict and increase positive affect. This work is important to consider for the present study because it provides support for the importance of positive interactions in general, and also helps to explain why the sharing of positive events (which provides an opportunity to increase mutual positive affect) may relate to satisfaction and stability within romantic relationships as well.

\section{Partners' Responses to Capitalization (Positive Event Sharing)}

Also of importance to interpersonal relationships is how individuals perceive responses to their capitalization attempts. When an individual shares a positive event, their perception of the response provided by the person they disclose to changes the impact of that event for the individual (Langston, 1994). According to Gable et al. (2004), there are two dimensions on which a romantic partner can respond to a disclosing partner's capitalization attempts: the activepassive and constructive-destructive dimensions. An active-constructive response demonstrates overt excitement while a passive-constructive response shows more silent or stoic support. An active-destructive response to a partner's capitalization attempt appears as if the partner is focusing on only negative aspects of the situation while a passive-destructive response can be viewed as disinterest (Gable et al., 2004). Only active-constructive are typically associated with better quality relationships (Gable et al., 2006). When partners typically respond in an activeconstructive or supportive manner to their partner's capitalization attempts, the disclosers report feeling happier with their relationships than those whose partners are typically more 
unsupportive in their responses (Gable et al., 2006). In the present study, the role of partner responses was further investigated in terms of its association to romantic relationship satisfaction.

One central reason that positive event sharing in romantic relationships can be seen as vital for relationship health is that the overall communication of positive events can predict not only stability in long-term relationships, but also which relationships will end. Gable et al. (2006) found that 4 out of 58 couples who reported for the longitudinal component of their study had ended their relationship, and that the intact couples differed from the couples who broke up only on their ratings of how partners typically responded to their positive event disclosures and on their interactions while discussing positive events. Couples who broke up reported that their partners typically responded to them in a less active-constructive and more passive-destructive manner, and this pattern was observed in their recorded discussions. Men in couples that broke up reported feeling less validated during their capitalization attempts, and women in these couples were observed as behaving in a less active and constructive manner during their partner's disclosures. Even though the number of couples who broke up is very small, these results still indicate the importance of responding appropriately to positive event sharing in romantic relationships.

\section{Attachment}

One major behavioral system that may affect how people respond when positive events occur to either themselves or their partner is attachment style. Attachment originates in infancy but is relevant across the lifespan, and it describes how individuals cope with distress and regulate their feelings of security (Bowlby, 1973; Cassidy, 1994; Collins \& Feeney, 2000; 2004). Children learn through early interactions with their parents whether or not the parent will 
respond consistently to their needs and function as a secure base or safe haven (Bowlby, 1973). Over time, children develop an attachment style through repeated interactions with their parents or primary caregivers, which comprises unconscious expectations for how others will behave called an internal working model (Bowlby, 1973; Cassidy, 1994; Diamond \& Fagundes, 2008). When parents respond in a consistent manner, children are more likely to become secure in that relationship, thereby forming a stable and secure attachment. However, when caregivers are not consistently responsive to a child's needs, that child is more likely to develop an insecure attachment (Ainsworth, Blehar, Waters, \& Wall, 1978; Cassidy, 1994). These early attachment styles and the internal working models they initiate can persist throughout the lifespan and affect other relationships in the individual's life, including romantic relationships (Bartholomew \& Horowitz, 1991; Bartholomew \& Shaver, 1998; Hazan \& Shaver, 1987).

In adulthood, individual differences in attachment have been shown to be most accurately conceptualized using two dimensions, anxiety and avoidance (Brennan, Clark, \& Shaver, 1998; Fraley \& Waller, 1998). Attachment anxiety is a preoccupation with relational closeness where people have a strong desire to be close to others and fear separation from those they are attached to. Attachment avoidance describes a general preference for emotional distance and a fear of becoming too close or reliant on an attachment figure. Secure individuals are low on both attachment anxiety and avoidance dimensions (Hazan \& Shaver, 1987; Mikulincer \& Shaver, 2005; Mikulincer \& Shaver, 2007). Early research on adult attachment style relied on categorical measures of attachment, where individuals were grouped into one of three (secure, anxiousambivalent, avoidant; Hazan \& Shaver, 1987) or four categories of attachment style (secure, preoccupied/anxious, dismissing/avoidant, or fearful) based on their views of themselves and others (Bartholomew \& Horowitz, 1991). However, the dimensional approach has been found to 
be more precise, and additionally can discriminate people into the traditional categorical styles (Brennan et al., 1998).

Adult attachment style can have important implications for romantic relationships. For example, Feeney and Noller (1990) found that individuals rated as secure were more trusting in their romantic relationships, while those with an avoidant attachment avoided intimacy and those individuals rated as anxiously attached were more neurotic and dependent in their relationships. Also, Simpson, Collins, Tran, and Haydon (2007) found that infants whose attachment style was classified as secure at 12 months of age had daily interactions with their romantic partners in adulthood that were rated as more positive than did those people classified as insecurely attached in infancy. This finding provides evidence for the long-term effects of early attachment style.

In addition, attachment style may have important implications for both the way individuals respond to their partner's positive event sharing and the way they interpret their partner's responses to their own capitalization (Hicks \& Diamond, 2008; Mikulincer \& Shaver, 2005). Individuals may respond to a romantic partner's attempts at disclosure differently depending on their attachment style in that secure individuals may be more supportive overall than insecurely attached individuals. For example, securely attached individuals (low on anxiety and avoidance) are more likely to be emotionally expressive and to experience more positive emotions than are insecurely attached people (Kerr, Melley, Travea, \& Pole, 2003), which may cause them to respond in a more supportive manner to their partner's capitalization attempts. They may also be less likely to feel threatened by the positive events that occur in their partner's life. Conversely, people who are high in the attachment dimension of anxiety may fear their partner leaving them when their partner experiences positive life events, because these positive events may be viewed as threatening. Finally, individuals high in attachment avoidance may 
respond in less supportive ways to their partner's positive event sharing because of their preference for emotional distance and their tendency to show less affection with partners (Hazan \& Shaver, 1987; Mikulincer \& Shaver, 2007). For example, women who are more avoidantly attached do not report as much of an increase in positive affect when sharing and hearing about positive events with their romantic partners than less avoidant women do (Hicks \& Diamond, 2008).

Attachment style also has implications for the way that people perceive their romantic partner's responses to their positive event sharing. Individuals who are high in attachment anxiety may need more support or reassurance from their partners during their own capitalization attempts, because they are more sensitive to their partner's perceptions of them and may need positive feedback to maintain their self-esteem and feelings of self-competence (Carnelley, Israel, \& Brennan, 2007). For example, Campbell, Simpson, Boldry, and Kashy (2005) found that people who were high in attachment anxiety felt more secure with their romantic relationships on days where they perceived higher levels of support from their partners. Conversely, individuals high in attachment avoidance may need less supportive responses to their own capitalization attempts because they may be less invested in the relationship and therefore be less emotionally invested in how their partner responds to them (Carnelley et al., 2007). Therefore, secure individuals may be more likely to feel satisfied with their partner's reactions to their positive event sharing because they may perceive the responses to be more supportive.

One study that investigated the relation between capitalization and attachment is that of Gable and colleagues (2006). They investigated positive and negative event sharing in romantic couples in a laboratory setting using both self-report and observational coding. No relation was 
discovered between positive event sharing and attachment, but this study had several limitations. Most of the participants had discussed the positive event with their romantic partner prior to sharing it with them in the laboratory discussion task, and $85 \%$ of participants had discussed it a fair amount or more. This may have impacted the reaction that the partner gave when told the event again, because they had already expressed their initial support when the event was first discussed. In this study, partners had also heard about the event prior to answering their questionnaires, but were asked to remember what they did rather than asked to respond anew to the disclosure.

Also, in the Gable et al. study the capitalization measures were given before and during the interactions between the partners, which may have made the participants more aware of their responses to their partners and primed them to act in a more supportive manner. In this study, participants completed the measures asking about their partner's general responses to positive event sharing at the lab visit, which for most participants was hours to days before they reported their partner's responses on the daily logs. In addition, the partners were not contacted by research staff until after the participants had already shared their partner's responses (therefore, ideally the partner did not know that their reactions to the participant's events were of interest until after they reacted naturally).

Finally, the relation between attachment and capitalization was tested through a correlation of observer codes of behavior during taped partner interactions and an attachment scale but did not assess for how the disclosing partner felt about their partner's reactions to their capitalization attempts. In this investigation, asking the participant and partner about how they interpreted the partner's response allowed for more of an understanding into how the couple was 
feeling about and processing that response. Therefore, the present study addressed each of the listed confounds within Gable et al. (2006).

Another study that aimed to understand the role of attachment in positive event sharing within romantic relationships was conducted by Hicks and Diamond (2008). Their study employed a daily diary method to investigate how sharing and hearing about daily positive events impacted positive affect in both relationship partners. They found some moderating effects for attachment, in that women who were higher in avoidance had less of an increase in positive affect after sharing and hearing about a positive event than did women lower in avoidance. In addition, highly anxiously attached women (as compared to less anxious women) reported less positive affect when their most positive event of the day involved their partners when compared to events that were not told to and did not involve their partner. However, there are two notable differences between this study and the present investigation. Specifically, in the present study participants completed the daily logs online which allowed for a determination of whether participants completed logs late, while the pen-and-paper diaries utilized by Hicks and Diamond did not allow for an accurate determination of the time that participants completed the logs. One other strength to the present study may lie in the outcome measure of relationship satisfaction. The results of the Hicks and Diamond study suggest that capitalization is bidirectional, and assessing relationship satisfaction (which has more to do with how the individual feels about the relationship itself) may be a more appropriate outcome measure than positive affect (which seems more personal and affected by a wider variety of influences).

\section{Support-seeking}

More commonly studied in close relationships is the sharing of negative life events or experiences with others in order to obtain support from those in the social network. This method 
of coping is often called support-seeking (Collins \& Feeney, 2000). The perception that a close partner is supportive and available during times of stress is associated with better quality relationships (Collins \& Feeney, 2000; Gable et al., 2006). However, providing the romantic partner with support during positive life events is different than providing the partner with support during negative life events. Gable and colleagues (2006) found that supportive responses during positive event sharing predicted relationship health better and more consistently than did supportive responses during the sharing of negative events. This shows that both play an important role in relationship satisfaction, and that being supportive across contexts has differing implications for relationships. To investigate the unique role of responses to positive events in understanding relationship satisfaction, the participant's general level of support-seeking was measured and controlled for as a possible confound in this investigation.

\section{Relationship Satisfaction}

The expression of both positive and negative emotions as well as general emotional expressivity in romantic relationships has been shown to be associated with better overall relationship satisfaction (Fardis, 2008). Also, the process of sharing life experiences with a romantic partner helps to build the friendship aspects of a relationship, which are important for maintaining the relationship (Gottman, 1982). However, as mentioned, supportive responses to a partner's positive event disclosures are related to more intimacy and higher satisfaction within relationships, and this finding is independent of both a partner's typical responses to negative events and the overall health of the relationship (Gable et al., 2004; Gable et al., 2006). Therefore, even though sharing negative emotions and events is imperative for feeling close to one's partner (e.g. through support-seeking), sharing positive events and emotions and 
responding appropriately to positive event disclosures appears to be critical components for continued satisfaction in romantic relationships as well.

\section{Gender}

Gender may play a significant role in an individual's responses to positive life events as well as in the sharing of positive events with romantic partners. For example, Morey, Keener, and Gentzler (2009) found that women were more likely to report maximizing responses (i.e., sharing and reflecting on positive events and emotions) and men were more likely to report minimizing responses (i.e., thinking that the feelings will not last, or having other negative thoughts) in response to positive life events. Women may also be more likely to savor positive events in general than men (Bryant, 1989; Bryant, Smart, \& King, 2005; Bryant \& Verhoff, 2007) and may be more likely to experience emotions more intensely than do men (Fujita, Diener, \& Sandvik, 1991). Specific to the sharing of positive events in relationships, Gable et al. (2006) found that for men, active-constructive responses to their capitalization attempts were viewed as supportive regardless of whether the event was rated by the individual as important or not important. If their partner gave them a positive response, they generally felt supported. However, for women, partner's responses to their important events was strongly related to perceived feelings of support in that only active-constructive responses led to feelings of being supported. If partners' responses were not overt and expressing a great deal of excitement, women did not feel that their partner was appropriately responsive. Also, in this study they found that for men, only the partner's responsiveness to their positive event sharing (not negative event sharing) affected their reported relationship well-being. For women both responses to negative and positive event sharing were related to current relationship well-being. Finally, moderating effects of attachment with positive event sharing were only found with women in prior research 
(Hicks \& Diamond, 2008). Since gender may play an important role in the sharing of positive events in romantic relationships, it was examined in the present study.

\section{Event Type}

Another factor that may influence whether how people react to positive events is whether they are interpersonal (occurring in the direct presence of others) or non-interpersonal in nature. Gender and attachment differences may be more readily apparent when reporting on interpersonal events, because these individual differences are developed in the presence of others (Gentzler, Kerns, \& Keener, 2010). For example, Gentzler et al. (2010) found that women used support-seeking more often when faced with a negative interpersonal event than a noninterpersonal event. In addition, when faced with positive events, participants were more likely to minimize or dampen their reactions to non-interpersonal events than they were to interpersonal events. Since event type has been shown to relate to the manner in which people cope with life events, it was examined in the present study.

\section{The Present Study}

The main purpose of this study was to investigate capitalizing responses (i.e., sharing positive events) and partners' responses to capitalization in adult romantic relationship partners. To better understand the implications of and putative contributors to these two sets of behaviors, each were examined for their association with relationship satisfaction and participants' attachment style.

\section{Research question 1: Do rates of capitalization relate to relationship satisfaction?}

Hypothesis 1a. Individuals who capitalized more often across a one-week period within their romantic relationships will have higher levels of satisfaction with their relationship partner. 
Hypothesis 1 b. Individuals who capitalized more often across a one-week period within their romantic relationships will have increased relationship satisfaction, but this association may be moderated by partner responses (see below).

\section{Research question 2: Does the type of partners' responses to capitalization attempts predict relationship satisfaction?}

Hypothesis 2a. Partners' active-constructive responses to the participants' capitalization attempts will predict the participant's greater relationship satisfaction over time. Both direct effects and an interaction effect (with the participant's overall positive event sharing) were examined. That is, participants whose partners gave more active-constructive than other types of responses should have higher rates of increased relationship satisfaction across the study than those whose partners gave less active-constructive responses.

\section{Research question 3: Does attachment style predict rates of capitalization?}

Hypothesis 3a. Attachment style was expected to relate to the number of positive events that the participants reported sharing with their romantic partners over the course of this study. It was expected that attachment security (low scores on both anxiety and avoidance) would be associated with higher rates of capitalization (i.e., sharing a greater number of positive events with their partners). Attachment avoidance was expected to relate to less capitalization (i.e., sharing of fewer positive events; Cassidy, 1994).

\section{Research question 4: Does attachment style predict responses to partner's positive} events?

Hypothesis 4a. It was hypothesized that attachment dimensions (anxiety and avoidance) would predict individuals' responses to their partner's capitalization attempts and how they perceived their partner's response to their own positive event sharing, such that those higher in 
attachment security would respond to their partner's capitalization attempts in more activeconstructive ways while those higher in attachment anxiety or avoidance would respond to their partner's capitalization attempts with less active-constructive responses.

Hypothesis $\mathbf{4 b}$. As an exploratory hypothesis, attachment security was expected to relate to having a more accurate perception of the partner's responses to capitalization attempts.

Hypothesis 4c. Also as an exploratory analysis, those higher in attachment anxiety or avoidance were expected be more negative in their interpretation of their partner's response to their capitalization attempts. This relation was hypothesized because attachment insecurity (higher scores on anxiety or avoidance) seem related to perceptual distortions, in that insecure individuals may be more likely to interpret their partner's response to them as passive or destructive independent of the partner's actual response.

\section{Method}

\section{Participants}

A total of 167 (137 women, 29 men) participants were recruited through the online SONA system at West Virginia University. Participants must have been enrolled in a psychology course, be 18 years of age or older, and in a committed relationship for at least 6 months. This length of time was adopted from Gable et al. (2006) and was chosen to assure that the couple had been together long enough to be familiar with one another's typical responses to shared positive events. The average relationship length was 22.67 months $(S D=14.91$; range 6 months to 66 months). The average age of primary participants was 19.78 years $(S D=1.97$; range of 18 to 33 years), and there were 50 freshman (29.9\%), 60 sophomores (35.9\%), 30 juniors (18\%), 22 seniors $(13.2 \%), 3$ graduate students $(1.8 \%)$, and $2(1.2 \%)$ other. It is unknown why graduate students and non-students would choose to participate, however the study did not specifically 
outline any restrictions for class standing that would preclude their participation. The sample was mostly Caucasian $(N=162 ; 97 \%)$, primarily heterosexual $(N=160,95.8 \%)$, and never married $(N=165 ; 98.8 \%)$.

In addition, participants were asked to provide their romantic partner's contact information so that their partners might participate in the study with them. A total of 108 romantic partners (87 men, 21 women) participated in this study. The average age of partners was 20.57 years $(S D=2.19$, range $=17$ to 29 years $)$, and the sample was also mostly Caucasian $(N=107,99.1 \%)$, heterosexual $(N=106 ; 98.1 \%)$, and never married $(N=107 ; 99.1 \%)$. There were 18 freshman (10.8\%), 32 sophomores (19.2\%), 15 juniors (9.0\%), 11 seniors $(6.6 \%), 4$ graduate students (2.4\%), and 27 other/not a student (16.2\%) partners. Participants and partners were both asked questions as manipulation checks (the month of their anniversary and where they met) to insure that they were in a relationship together if their data appeared questionable for any reason during analysis. Visual inspection of the answers given for where the couple met did not indicate any major discrepancies, and correlations conducted between the participant and partner on their reported anniversary indicated a high level of agreement $(r=.96, p<.001)$. Correlations between participant's and partner's attachment indicated that anxiety and avoidance in partners $(r=.53, p<.001)$ and in participants $(r=.52, p<.001)$ were correlated. In addition, attachment anxiety in participants was correlated with attachment avoidance in partners $(r=.29$, $p=.005)$, indicating that highly anxious participants were more likely to have partners high in avoidance. See Table 2 for descriptive information across scales, gender, and event type.

The participant was awarded extra credit in a psychology course for their participation, while their partner (who did not have to be affiliated with the university) received a choice of extra credit in a WVU psychology course (if they were enrolled in one also), donating the earned 
credit to their partner, or a monetary payment. Participants and partners were instructed that all of their information would be confidential, and that they and their partner would be identified and paired together only by an ID number. They were also told that they could withdraw from the study at any time without fear of penalty.

Participants whose partners completed the study did not differ from those whose partners failed to complete the study on the majority of the variables of interest, including participant gender $(t(164)=-.37, n . s$.$) , the length of the relationship (t(164)=-.96, n . s$.$) , participant's$ attachment anxiety $(t(165)=-.55, n . s$.$) or attachment avoidance (t(165)=-.51, n . s$.$) ,$ participant's time 1 relationship satisfaction $(t(165)=-1.06$, n.s. $)$, participant's overall capitalization scores at time $1(t(162)=-1.38, n . s$.$) and time 2(t(118)=-1.90, n . s$.$) ,$ participant's support seeking $(t(165)=.03$, n.s. $)$, or the proportion of events they reported over the week vs. those they shared with partners $(t(158)=-1.14, n . s$.$) . However, couples where the$ partner completed the study did differ from those in which the partner did not complete the study in two factors; the overall number of logs participants completed over the study period $(t(165)=$ $-5.83, p<.001)$ and the participant's relationship satisfaction at time $2(t(118)=-2.15, p<.05)$. For both the number of logs completed $(M$ for completers $=6.49 \operatorname{logs}, M$ for non-completers $=$ $4.78 \operatorname{logs})$ and time 2 relationship satisfaction $(M$ for completers $=6.22, M$ for non-completers $=$ 5.90), the couples in which partners completed the study scored higher than those whose partners did not.

Finally, of the 108 completed participant-partner dyads, 16 couples were excluded from these analyses for either the participant failing to respond to enough logs over the study period $(>5)$ to demonstrate sufficient adherence to protocol, or for reporting only on events that took place in the company of their partner. This 5-log cutoff was selected based on prior research 
(Gable et al., 2004; who reported average completion rates of 5.1 out of 7 logs). Therefore, the analyses under investigation within the present study were conducted with a final sample of 92 dyads.

\section{Procedure}

Participants registered for the study using the online SONA system. The participant was given general information about the study's protocol and was asked to schedule a lab appointment where they completed the first part of the study. The participant reported to the lab during the scheduled time to meet with the researcher, and was asked for their informed consent to participate, their demographic information (age, race, sex, year in school, sexual orientation, and length of time in current relationship), and for the email address (and later, telephone number) of their romantic partner. The participant was informed at that time that their partners would be contacted during the course of the study and would be questioned about specific events that the participant reported were shared during the study period. After this information was obtained participants completed the general Perceived Responses to Capitalization Attempts (PRCA) measure, the Experiences in Close Relationships (ECR) scale, the Relationship Assessment Scale (RAS), and the Network of Relationships Inventory: Social Provisions version scale (NRI). Before leaving the lab, the participant received instructions to begin their daily logs online beginning on the closest Monday night.

Starting the Monday night following the lab visit (or that night, if lab participation occurred on a Monday) the participant accessed the internet and logged the most positive event that occurred that day as well as their reactions to that event, and if they reported telling the partner about that event, they completed a revised Perceived Responses to Capitalization Attempts measure to assess perceived partner responses to capitalization attempts for that 
specific event. They continued to log events over the rest of that calendar week ( 7 total), and were requested to complete them by midnight of each designated night. After they completed their final log online at the end of the one-week period they were directed to the study questionnaires where they completed the general Perceived Responses to Capitalization Attempts measure and the Relationship Assessment scale again. This allowed for an assessment of change over time, which could be especially important when considering how individual differences in conjunction with behaviors across a one-week period impact relationship satisfaction. When these questionnaires were completed the participants were informed that they had completed the study and would receive extra credit for their participation.

During the laboratory visit, the participant was required to provide their partner's email address (and, later, telephone number). Once the participant completed their portion of the study (after the 7-day period), researchers chose one positive event that was emotionally salient to the participant and that they reported sharing with the partner. Ratings of how good the event was and event importance were averaged together to determine the most salient positive event. If multiple events were reported with the same averaged ratings, the researcher chose the event at random after excluding events that happened in the presence of the partner. Several participants did have multiple events with the same goodness/importance composite score (57 out of 92 participants; 62\%), and therefore their events were chosen at random.

Then, information about the study was emailed to the participant's romantic partner with a password so that only the partner could access their portion of the study. The partner accessed the study online, where they were first asked if they consented to participate. Then they were asked for their demographic information, as well as if they remembered their partner sharing the chosen event with them. If they did not remember the event, they were asked to stop the survey 
and email the researcher, who then chose the reported event with the next highest rating and emailed the partner a revised email asking about that event. Only one partner emailed the research to state that they did not remember the chosen event. If the partner did remember the event, they were asked about their reactions to that event in open-ended questions. After that, the partner completed the Experiences in Close Relationships scale (ECR) and the Relationship Assessment Scale (RAS). They then completed a modified Perceived Responses to Capitalization Attempts (PRCA) measure that asked how the partner responded to the positive event in question. When both of these sections were completed, the partner was informed that they completed their part of the study and were asked to specify their desired incentive. See Table 1 for a listing of the measures that the participant and their partner completed at each time period over the course of this study.

\section{Materials}

Logging of positive events. To record positive events and positive event sharing each day, participants completed logs online every day for one week (Monday - Sunday) before going to bed. The one-week time span was chosen (rather than a shorter time period such as 1 day) to maximize the likelihood that participants would experience a positive event that was important to them and that they would share with their partner during the duration of the study. The same time period was utilized by Gable et al. (2004). A longer time period may have been more desirable (around 2 weeks, as was the case in Langston, 1994), but was probably not feasible in this population due to lack of available additional incentives beyond the one-week period. Participants were able to report anywhere from one to ten positive events per day; however no participants reported more than 3 events on an individual daily log. Participants were instructed to fill out the log before midnight of that night. 
This method of obtaining information about positive events and capitalization attempts is different from the work done by Gable et al. (2006) because our participants were not remembering a past positive event to share with their partners, but were reporting on that event at the end of the day when it occurred. This should also remove any effects of the partner knowing about the event before the experiment started, and therefore having a muted response to its disclosure, which was a potential confound in the Gable (2006) investigation. It should also help to minimize memory distortions for the event that are likely to occur over a longer delay period.

Participants in general were compliant with the daily log protocol; 106 participants $(63.5 \%)$ completed 7 logs, $24(14.4 \%)$ completed 6 logs, $10(6 \%)$ completed 5 logs, $4(2.4 \%)$ completed 4 logs, 4 (2.4\%) completed 3 logs, 7 (4.2\%) completed 2 logs, 5 (3\%) completed 1 $\log$, and 7 did not complete any logs (4.2\%). Also, the dyads included in the final sample of 92 couples had to have participants who completed at least 5 logs in order to be eligible for analysis, and most completed $7 \operatorname{logs}(81.5 \%)$, while 13 completed $6 \operatorname{logs}(14.1 \%)$ and 4 completed $5 \operatorname{logs}$ $(4.3 \%)$.

When completing the log, participants were asked to describe their most positive event of the day and were asked to rate their reactions to that event. For example, they were asked how important the event was to them, how happy or excited they felt when it first occurred, how happy they feel about it currently, and if they expected any other rewards or positive circumstances to occur as a result of that particular event. Participants were asked each day if they shared the positive event that they reported or if they planned to share the event with anyone else, specifically their romantic partner. If they did share the event, they were asked to describe their partner's response to the disclosure in an open-ended format, which was coded later on the active-passive and constructive-destructive dimensions by two independent raters. Kappas for 
these coded dimensions indicated a moderate degree of agreement ( .83 for participant's reported responses). Short responses (i.e. "he was happy") were difficult to code on the active-passive dimension, so coders were instructed to code responses as passive when they simply said that someone was happy, angry, sad, etc. and were told to code responses as active when more detail or a qualifier was provided (i.e. "she was very happy" or "he was so excited for me").

In addition to this open-ended question the participants completed a revised Perceived Responses to Capitalization Attempts measure that had been altered to ask about specific events. Finally, the event type (interpersonal vs. non-interpersonal) was coded by two independent raters. Raters were told to code events as interpersonal in nature when another person was central to the activities reported, and to code events as non-interpersonal when the focus of the good event was unrelated to other people. Kappa indicated a high level of agreement across raters (.91). The final codes indicated that of participant's chosen events, $36(39 \%)$ were interpersonal in nature (for example, "I had taco night with my girlfriends" while 56 (60.9\%) were noninterpersonal (for example, "I got my teeth cleaned at the dentist.)"

Perceived partner responses to capitalization attempts. The participant completed Gable et al.'s (2004) Perceived Responses to Capitalization Attempts Scale (PRCA), which is a 12-item measure designed to assess how individuals perceive their partner's typical reactions to their capitalization attempts. The participant completed this generalized measure at both Time 1 (the laboratory visit) and Time 2 (online). This measure uses the stem "When I tell my partner about something good that has happened to me..." and includes 3 questions for the activeconstructive, 3 for the passive-constructive, 3 for the active-destructive, and 3 for passivedestructive response dimensions. Participants are asked to rate their partner's typical response on a scale of 1 to 7, with 1 denoting "not at all true" and 7 denoting "very true." Reliability for the 
Perceived Responses to Capitalization Attempts measure has been demonstrated with both men $(\alpha=.84)$ and women $(\alpha=.81)$ in past studies, and was also assessed in this investigation (values ranging from $\alpha=.69$ to .83 for time 1 and $\alpha=.77$ to .93 for time 2$)$. These reliability values were obtained for each 3-item subscale individually, as described in Gable et al. (2004). An example question for the active-constructive dimension is "I sometimes get the sense that my partner is even more happy and excited than I am." This scale provides a composite score for capitalization when the values of the passive-constructive, active-destructive, and passive-destructive scales are subtracted from the score obtained on the active-constructive scale (Gable et al., 2006).

In addition to the general Perceived Responses to Capitalization Attempts measure, the participants completed an event-specific Perceived Responses to Capitalization Attempts scale for each positive event that they reported sharing with their romantic partner on their daily logs. These revised measures were adapted by the researcher from the original Perceived Responses to Capitalization Attempts scale to assess how the participant perceived the partner's responses to each specific event that they reported sharing. For example, instead of being asked if "My partner often asks a lot of questions and shows genuine concern about the good event" the participant was asked if "My partner asked a lot of questions and showed genuine concern about this good event." Reliability was demonstrated for the event-specific logs over the 7-day period (values ranging from $\alpha=.50$ to .95 ).

Finally, the Perceived Responses to Capitalization Attempts measure was modified to assess the partner's perception of how they responded when the participant disclosed to him or her about the specific positive event under investigation. Partners completed this measure in addition to answering open-ended questions about their responses to the participant. An example of the modifications to the general Perceived Responses to Capitalization Attempts measure is 
that instead of being asked if "My partner often asks a lot of questions and shows genuine concern about the good event," the Perceived Responses to Capitalization Attempts measure for partners asked "I often ask my partner a lot of questions and try to show genuine concern about the good event." Reliability for the Partner-modified Perceived Responses to Capitalization Attempts measure ranged from $\alpha=.73$ to .90 .

Partner's reported response to capitalization attempts. At the end of the participant's one week logging period, the partner was asked how they responded to one of the events logged by the participant. The chosen event was one that generated a strong positive emotional reaction and was rated as important by the participant and one that the participant reported sharing with the partner. Asking the partner about their reactions allowed for a comparison of how each person perceived the partner's response to the participant's capitalization attempt. In an openended question format, the partners were asked "How did you respond when your partner told you about this event?" The response blanks (for both participants and partners) for open-ended responses were space limited, to assure that only the most pertinent information was provided by respondents, as well as to ease the coding process. Reported responses were coded on the activepassive and constructive-destructive dimensions by two independent raters. Kappas for these coded dimensions indicated a moderate degree of agreement (.70 for partner's reported responses).

Attachment. To measure attachment in both romantic partners, the Experiences in Close Relationships Questionnaire (ECR) was utilized (Brennan et al., 1998). Participants completed this measure at Time 1 and partners completed it during their portion of the study (Time 2). This questionnaire was designed to measure the attachment dimensions of avoidance (reliability of $\alpha$ $=.94$ ) and anxiety (reliability of $\alpha=.92$; Tsagarakis, Kafetsios, \& Stalikas, 2007) within close 
relationships. Reliability within this sample was also demonstrated, with attachment anxiety $\alpha=$ .90 and attachment avoidance $\alpha=.91$ for participants, and $\alpha=.90$ for anxiety and $\alpha=.92$ for avoidance in partners. The measure has been shown to correlate highly with scales measuring similar constructs, in that attachment avoidance correlates with measures regarding discomfort with close relationships and attachment anxiety correlates with other measures of fear of rejection and with jealousy (Brennan et al., 1998). It has 36 items rated on a Likert scale with 1 meaning "strongly disagree" to 7 denoting "strongly agree." Example questions for this measure include "I get uncomfortable when a romantic partner wants to be very close (attachment avoidance)" and "I often worry that my partner will not want to stay with me (attachment anxiety)."

Relationship satisfaction. To measure satisfaction with the romantic relationship, both partners completed the Relationship Assessment Scale (RAS; Hendrick, 1988). Participants completed this measure at both Time $1(\alpha=.79)$ and Time $2(\alpha=.82)$ which allowed for a comparison of satisfaction across the beginning and end of the study, while partners completed it during their portion of the study (Time $2 ; \alpha=.83$ ). This questionnaire includes 7 items and is typically rated on a 5-point Likert scale. However, for this investigation the scale was expanded to a 7-point Likert scale with the intent of increasing sensitivity to small changes in satisfaction over time; the scale ranged from 1 denoting "low satisfaction" to 7 denoting "high satisfaction." An example question from this measure is "In general, how satisfied are you with your relationship?" This scale has been shown to measure not only satisfaction with the relationship, but is also an indicator of which relationships will end within a two-month follow-up period (correctly identifying $91 \%$ of the couples that stayed together and $57 \%$ of those who ended the relationship; Hendrick, Hendrick, \& Adler, 1988). Reliability in other studies has been 
demonstrated for this measure at the same general level as within this sample $(\alpha=.82$; Hendrick, 1981; 1988; Hendrick et al., 1988). In addition, the RAS has also been shown to have adequate test-retest reliability (.85 over a 6-7 week period; Hendrick, Dicke, \& Hendrick, 1998).

Support-seeking. To measure general support-seeking behaviors, participants completed the Network of Relationships Inventory: Social Provisions version (NRI; Furman, 1996) at Time 1. This 39-item measure assesses a broad range of attitudes and behaviors that individuals experience when interacting with a specific person. Responses are rated on a 5-point Likert scale, from 1 being "little or none" to 5 being "the most" or from 1 being "S/he always does" to 5 being "I always do." The scale as used for this study has 12 subscales; companionship, instrumental aid, intimacy, nurturance, affection, admiration, reliable alliance, satisfaction, support, conflict, antagonism, and criticism. From these 12 subscales two overarching factors can be derived, the social support (consisting of companionship, instrumental aid, intimacy, nurturance, affection, admiration, reliable alliance, satisfaction, and support) and negative interchanges (consisting of conflict, antagonism, and criticism) factor. For this investigation the 27-item social support factor was analyzed so that general levels of support-seeking could be controlled for in the statistical analyses. Examples of questions from the social support factor include "When you are feeling down or upset, how often do you depend on this person to cheer things up?" and "How much does this person help you figure out or fix things?" Reliability has been demonstrated for the overall Network of Relationships Inventory $(\alpha=.81$ to .90 ; Furman \& Buhrmester, 1992; Holladay \& Kerns, 1999). Reliability was also demonstrated for the overall scale $(\alpha=.85)$ and for the support seeking scale $(\alpha=.82)$ in this study.

\section{Results}


Several preliminary analyses were conducted. First, variables of interest were inspected with respect to their distributions (e.g., normality, outliers) and missing data. Variables were considered significantly skewed if the absolute value of skewness was higher than 3.2 (Tabachnick \& Fidell, 2007). The proportion of events participants shared with partners vs. those they did not was negatively skewed (absolute value of 5.82) so it was reflected and log transformed. Time 2 relationship satisfaction (absolute value of 3.76) and the participant's total capitalization score (absolute value of 4.48; on the event-specific Perceived Responses to Capitalization Attempts scale) for the chosen events were also negatively skewed so they were reflected and square root transformed. Participant's attachment avoidance (value of 4.79), partner's attachment avoidance (value of 5.19) and partner's attachment anxiety (value of 4.58) were also positively skewed so a square root transformation was applied. Relationship satisfaction at Time 2, capitalization scores for partners and participants, partner attachment (avoidance and anxiety) and the difference score between partner reported and participant reported responses were found to have a small amount of missing data (less than 10\%), so variable mean imputation was utilized for those variables. Cronbach's alphas were analyzed for each of the scales to determine reliability. Kappas were conducted across all coded data to determine inter-rater reliability, and any discrepancies between raters were discussed between the two coders and a final code was chosen for these analyses.

Second, the study included multiple assessments of partners' responses to the participant's capitalization: the participant's general Perceived Responses to Capitalization Attempts (PRCA) measure, the participant's daily PRCA measure to specific reported events, and the partners' PRCA measure in response to the participant's specific events. Also, both the participant and the partner were asked to provide open-ended accounts of the partners' responses, 
which were coded. As part of the preliminary analyses, associations among all of these reports were examined by correlations. See Table 3 for detailed information on the most pertinent correlations across raters and scales, including information on how the varying measurements of partner response mentioned above were correlated.

The proposed study had indicated that active-constructive strategies alone would be utilized in the main analyses. However, it was decided that it would be more appropriate to use the overall scores obtained from the Perceived Responses to Capitalization Attempts measure (rather than just the active-constructive subscale) because there was a possibility that partners could generally respond in both a positive, overt manner (active-constructive) while also often being more passive in their response on other occasions (passive-constructive). That is, the four response styles derived from the Perceived Responses to Capitalization Attempts measure were not necessarily mutually exclusive, and using the scaled score allowed for a more precise indication of how the partner was responding. Finally, because there were so many participants who missed at least one log over the course of this study (and, therefore, did not have the opportunity to report an event for that day), the proportion of events reported on the logs to those participants reporting sharing with partners (referred to as the proportion of reported vs. shared events) was used as the index of capitalization frequency for these analyses.

Gender and event type (interpersonal vs. non-interpersonal) were considered in the preliminary analyses as well, with t-tests being conducted to determine if differences existed between the two types of events on any of the measured constructs. Few reliable differences were found that required the inclusion of covariates. Specifically, event type was only included for its relation to the proportion of events shared over the week $(t(90)=-2.18, p=.03)$, indicating that participants were sharing a greater proportion of their interpersonal events with 
partners (see Table 2). Partner gender was included for its marginal relation to the partner's reported responses on the event-specific Perceived Responses to Capitalization Attempts measure $(t(90)=3.88, p=.09)$, with men $(M=-2.95)$ reporting slightly less active-constructive responses than women $(M=1.00)$. See Table 2 for descriptive information on the major variables of interest across participant gender and event type.

\section{Research Question 1: Do Rates of Capitalization Relate to Relationship Satisfaction?}

Hypothesis 1a. To test the hypothesis that individuals who capitalized more often across a one-week period within their romantic relationships would have reported higher levels of satisfaction with their relationship partners, a bivariate correlation analysis was conducted between the participants' time 1 relationship satisfaction and the proportion of reported vs. shared events. Results indicated a correlation of $r(90)=.30, p=.004$, indicating that higher relationship satisfaction scores at the start of the study are related to sharing a greater proportion of positive events over the course of the study.

Hypothesis 1b. To test the hypothesis that individuals who capitalized more often across a one-week period within their romantic relationships would have increased relationship satisfaction, but that this association may be moderated by partner responses, multiple linear regression analyses were conducted to predict participants' time 2 relationship satisfaction. Time 2 relationship satisfaction was regressed onto the proportion of shared events. Participants' time 1 relationship satisfaction was included as a covariate so that the result informed on change in relationship satisfaction across the one-week interval. The participants' support-seeking was also included as a covariate to examine the effects of positive event sharing above and beyond the effects of perceiving general support from partners. In addition, because type of event (interpersonal vs. non-interpersonal) was found to relate significantly to the proportion of 
reported vs. shared events $(t(90)=-2.18, p=.03)$, event type was included in these analyses as a covariate. Finally (as described below), partner's response (participant's event-specific Perceived Responses to Capitalization Attempts measure) was included in the model as a predictor.

Results indicate that the overall regression analysis was significant $F(6,85)=15.74, p<$ $.001, R^{2}=.53$. However, further examination showed that the participant's proportion of reported vs. shared events (or, how often the participant shared positive events with the partner across the one-week period) was not predictive of the participant's time 2 relationship satisfaction ( $\beta=.04$, $p=.65)$. Support seeking $(\beta=.17, p=.11)$ and event type $(\beta=-.01, p=.90)$ also were not predictive of time 2 relationship satisfaction. As would be expected, participant's time 1 relationship satisfaction was a significant predictor of time 2 relationship satisfaction ( $\beta=.73, p$ $<.001)$. Therefore, the results of this analysis suggest that relationship satisfaction is not impacted over time by how often the participant shares positive events with the partner.

\section{Research Question 2: Does the Type of Partners' Responses to Capitalization Attempts Predict Relationship Satisfaction?}

Hypothesis 2a. The next hypothesis under investigation was that partners' activeconstructive responses to the participants' capitalization attempts would predict the participant's greater relationship satisfaction over time. This hypothesis was tested in conjunction with $1 \mathrm{~b}$ above, and was analyzed using the results of the same regression analysis used to test $1 \mathrm{~b}$. Specifically, using the participants' Time 2 relationship satisfaction as the dependent variable, multiple regression analyses were conducted with the following predictors: the participants' proportion of reported vs. shared events, the participants' time 1 relationship satisfaction, and the participants' perception of their partners' response to their specific event (on the event-specific Perceived Reactions to Positive Events measure), as well as an interaction term between the 
proportion of reported vs. shared events and the participants' perception of their partner's response (again, using the event-specific Perceived Reactions to Positive Events measure). All interaction terms were centered before being multiplied together. The participants' overall level of support-seeking was added as a covariate to address how available, warm, and helpful participants' view the partner to be generally.

Results from this analysis show that the partners' reaction to the chosen event (derived from the participants' event-specific Perceived Responses to Capitalization Attempts measure) was predictive of participant's relationship satisfaction at time $2(\beta=.18, p=.03)$. The interaction term between the proportion of reported vs. shared events and the participant's perception of their partners response was non-significant $(\beta=-.08, p=.31)$. In comparison to the significant relation between perceived partner responses to positive events and satisfaction over time, support seeking was not related to relationship satisfaction $(\beta=.17, p=.11$ as mentioned above). Even though the difference between these two numbers is slight, this finding still suggests that reactions to positive events are an integral component of relationship satisfaction, even when considering how supportive and present participants perceive their partners to be in general.

\section{Research Question 3: Does Attachment Style Predict Rates of Capitalization?}

Hypothesis 3a. Attachment security was expected to relate to the number of positive events that the participant reported sharing with their romantic partner over the course of this study. To test this association, multiple linear regression was used. The outcome variable was the participant's proportion of shared events. Predictor variables include the participant's attachment anxiety and avoidance as well as the interaction between anxiety and avoidance. Event type was included as a covariate because of its relation with the proportion of events shared. 
Results for this analysis demonstrate that the overall model was significant at $F(4,87)=$ 2.76, $p=.03, R^{2}=.11$. Participant's attachment avoidance $(\beta=.05, p=.67)$ and the interaction term between avoidance and anxiety $(\beta=.03, p=.80)$ were not related to the proportion of events shared over the course of the study. However, participant's attachment anxiety $(\beta=-.28, p$ $=.02)$ and the type of event $(\beta=-.22, p=.04)$ were predictive of the proportion of events reported on the logs to those shared with partners. These findings indicate that less anxiously attached participants are sharing a higher number of positive events that they report on their logs with their romantic partners, and that participants are sharing a greater number of interpersonal events.

\section{Research Question 4: Does Attachment Style Predict Responses to Partner's Positive}

\section{Events?}

Hypothesis 4a. It was hypothesized that attachment dimensions (anxiety and avoidance) would predict individuals' responses to their partner's capitalization attempts and how they perceived their partner's response to their own positive event sharing. First, to examine the relation between the partner's attachment anxiety and avoidance with partner responses, regression was used with the partner's event-specific Perceived Responses to Capitalization Attempts (PRCA) measure and the participant's PRCA measure as potential DVs and partner attachment anxiety and avoidance as predictors. Partner gender was included as a covariate due to its marginal relation to the partners' reported responses on the PRCA measure $(t(90)=3.88, p$ $=.09$ ). To examine the participant's attachment style and their perception of partner responses, regression was used, with the outcome being the participant's Perceived Responses to Capitalization Attempts measure and the predictors being the participant's attachment anxiety and avoidance. 
Results for the first regression (using partner's attachment and gender to predict the participant's perception of the partner's response) indicated that the overall analysis was significant at $F(3,88)=2.87, p=.041, R^{2}=.09$. However, none of the individual predictors were significantly related to the participant's perception of their partner response (partner gender $\beta=$ $.02, p=.87$; partner attachment avoidance $\beta=-.15, p=.21$; and partner attachment anxiety $\beta=-$ $.19, p=.13)$. Next, the regression predicting the partner's self-reported response from the partner's gender and attachment was conducted, and results indicated that the overall model was also significant $F(3,88)=11.04, p<.001, R^{2}=.27$. However, in this analysis all of the individual predictors were significant (partner gender $\beta=.22, p=.02$; partner attachment avoidance $\beta=-.30, p=.01$; and partner attachment anxiety $\beta=-.28, p=.01$ ), indicating that the partner's individual differences are better predictors of what the partner reported doing in response to the shared event than what the participant said the partner did. The results of this regression indicate that women are more likely to respond in a more active-constructive manner when their partner shares a positive event. In addition, the partner's attachment style impacts how they report reacting to positive event disclosures. Specifically, partners lower in attachment avoidance and anxiety are more likely to respond in a positive (active-constructive) manner.

Results for the second part of hypothesis 4 a (predicting participant report of their partner's behavior from the participant's attachment) indicate a significant overall regression analysis $\left(F(2,89)=9.65, p<.001, R^{2}=.18\right)$. In this analysis participant attachment avoidance $(\beta$ $=-.18, p=.11)$ was not a significant predictor, but participants' attachment anxiety $(\beta=-.30, p=$ .01) was significantly related to the participant's report of their partner's response to their chosen positive event. This suggests that participants lower in attachment anxiety are more likely to 
report that their partner responded to their capitalization in a positive (active-constructive) manner.

Hypothesis $\mathbf{4 b}$. To test the exploratory hypothesis that attachment security would relate to having a more accurate perception of the partner's responses to capitalization attempts, a difference score was obtained by subtracting the participant's perception of their partner's response from their partner's reported response. The absolute value of this difference score was used in the analysis so that lower scores (closer to zero) indicate greater accuracy. As this hypothesis was exploratory, attachment avoidance and anxiety were entered on their own step before introducing their interaction on Step 2. Therefore, the regression analysis was conducted using the absolute value of difference scores as the outcome variables and the participant's attachment anxiety and avoidance (on Step 1) as well as their interaction (on Step 2) as predictors.

Results of this analysis demonstrated that the first step of this regression was significant $\left(F(2,89)=3.21, p=.045, R^{2}=.07\right)$. Attachment avoidance was a significant predictor of the difference score $(\beta=.27, p=.03)$ while anxiety was not significant $(\beta=.02, p=.87)$. The second step of the model was non-significant $\left(F(3,88)=2.20, p=.09, R^{2}=.07\right)$ with the interaction term failing to predict the outcome $(\beta=.05, p=.63)$. Findings from this regression suggest that participant attachment avoidance plays a role in the degree to which participants and partners are discrepant, however this relation is obscured when attachment security is included in the model.

Hypothesis 4c. To test the exploratory hypothesis that those individuals higher in attachment anxiety or avoidance would interpret their partner's responses to their capitalization attempts in a more negative manner, a regression analysis was conducted with the difference 
score (obtained by subtracting the participant's perception of their partner's response from their partner's reported response) as the outcome variable, and the participant's attachment anxiety and avoidance scores as well as the interaction between participants' anxiety and avoidance as predictors.

Results of this regression analysis were non-significant $\left.F(3,88)=1.85 p=.15, R^{2}=.06\right)$, with participant attachment anxiety $(\beta=.13, p=.29)$ and avoidance $(\beta=.17, p=.18)$ as well as their interaction $(\beta=-.09, p=.44)$ not contributing significantly to distorted perception. This shows that the degree of attachment insecurity is not related to differences between participant and partner report. In addition, the lack of findings for this analysis also suggests that secure individuals (those low in anxiety and avoidance) do not have positively distorted perceptions of their partner's response.

\section{Discussion}

The primary aim of this research was to investigate capitalizing (positive event sharing) and partners' responses to capitalization in adult romantic relationship partners. To better understand these concepts, each was examined for their association with relationship satisfaction and attachment.

\section{Positive Event Sharing}

The first research question under investigation was that participants who shared more positive events with their romantic partners over the course of the study would have higher relationship satisfaction with that partner. This hypothesis was tested through both correlation and regression. Results of the correlational analysis suggested a relation between sharing positive events and relationship satisfaction, but results of the regression analysis suggest that the sharing of positive events over a 1-week period does not significantly relate to relationship satisfaction 
across that week. Within the correlation analysis it is impossible to determine the direction of the found relationship, however the temporal component in the measurement of these variables does allow for an understanding of which came first. Specifically, relationship satisfaction at time 1 was related to more sharing across the week, but sharing did not relate to the level of change in relationship satisfaction across the week. This pattern of findings suggests that those who are already happier and more satisfied with their partner feel more inclined to self-disclose (Finkenauer, Engels, Branje, \& Meeus, 2004). Therefore, while there was a significant positive relation between capitalization and satisfaction, it appears that it was not simply the frequency in which individuals shared events with their partners that predicted their relationship satisfaction.

\section{Partner's Responses to Positive Event Sharing}

Within the second research question, it was predicted that partner's responses would relate to relationship satisfaction over time, in that those participants who reported receiving a more positive (active-constructive) response from their partner when sharing an event would report more satisfaction in their relationship. Results indicated that participants who reported that their partners responded in a more active-constructive and less passive/destructive manner indeed reported greater relationship satisfaction over the course of this study. In addition, this relation was found even when accounting for participant report of how supportive and reliable their partners are generally. Therefore, the results of the first and second hypotheses indicate that sharing positive events with one's romantic partner is related to satisfaction in the relationship, perhaps even more important than just knowing the partner is there for them in general. This is in support of previous research by Gable and colleagues (2004, 2006), who also found that supportive responses to capitalization were related to relationship health (i.e., marital satisfaction and intimacy) independent of supportive responses to negative events. 
There are several reasons why supportive responses to positive event disclosures may be important independent of receiving support more generally. When partners respond in an activeconstructive manner to positive event sharing, they are saying at least two things to the discloser. The first is that the event itself is important, and the second is that the partner understands the participant enough and has built enough intimacy with that person to know how important that event is to them (Gable et al., 2006). Negative events are often negative "on the surface," in that they would be negative to anyone who experienced them. For example, if one was fired from a job, this would be interpreted negatively by almost anyone in that situation. In contrast, if one went to the dentist for a cleaning and shared that as a positive event, the partner's enthusiastic response would require that the partner know that the participant has been without dental insurance for some time. When participants share negative events with their partners (as a component of support-seeking), the participants have to admit that something is wrong in their lives to their partner, which can be threatening to the self (Fisher, Nadler, \& Whitcher-Alagna, 1982). Participants would have to admit that they could not handle the event on their own, and may have to ask the partner to provide emotional or physical support. In essence, responding positively to positive event disclosures allows the partner the chance to bolster the participant's self-esteem, feelings of intimacy, and positive affect, while responding well to negative events may help the participant feel supported but at a possible cost to their feelings of self-efficacy. Because of the very different underlying messages that receiving support with positive versus negative events entail, it is understandable that supportive responses to positive events may be more associated with relationship health than just supportive responses in general.

\section{The Role of Attachment}


The final two research questions under investigation in this study were aimed at understanding the role that participants' and partners' attachment may have on positive event sharing. Specifically, those who were less secure, particularly those who were high in attachment avoidance, were expected to share the fewest number of positive events with their partners. This hypothesis was partially supported in that participants lower in attachment anxiety reported sharing more positive events with their partners than participants high in attachment anxiety. In some ways, this finding makes sense in light of the literature on attachment anxiety. Lower levels of attachment anxiety may be vital to one's ability to recognize positive life events as positive, and to want to share those events with others. Mikulincer and Sheffi (2000) found that participants high in attachment anxiety did not experience an increase in positive mood in response to remembering a recent positive event, and did not perform better on subsequent problem-solving and creative tasks. In addition, Gentzler et al. (2010) found that even when a positive interpersonal event was staged, participants high in attachment anxiety reported a higher percentage of negative thoughts unrelated to the study. These findings suggest that participants high in attachment anxiety attend to threats at a higher level, and therefore have a more difficult time with rumination and with down-regulating their negative affect. Anxiously attached people may remember times in the past where they have experienced positive affect and lessened their attention to possible threats, only to be hurt later on (Mikulincer \& Sheffi, 2000; Shaver \& Mikulincer, 2008).

In addition, this analysis indicated that participants were sharing a greater number of interpersonal events with their partners than non-interpersonal events. This was similar to prior research which suggests that people would be more likely to share or to not minimize the impact of interpersonal events (Gentzler et al., 2010). One possibility for why this finding might be 
present is that many of the reported non-interpersonal positive events were school-related, and participants likely experience these types of events often. The interpersonal events reported may have been more important to participants because of the social resource building that can occur when experiencing positive emotions in the presence of others (Fredrickson, 1998). Finally, this may have been a function of the unbalanced gender ratio within the participant sample, as gender differences are seen more often within interpersonal events (Eschenbeck, Kohlmann, \& Lohaus, 2007), and women have been shown to discuss negative interpersonal events (via support seeking) more often than men (Gentzler et al., 2010).

In the last research question, the relation between (perceived) partner responses and attachment was explored. Attachment was expected to predict partner's responses to the participant's capitalization attempts as well as the participant's perception of their partner's responses. Specifically for partner responses, expectations were that those partners higher in attachment security would respond to the participant's capitalization attempts more positively while those higher in attachment anxiety or avoidance would respond to the participant's capitalization attempts with less positive (active-constructive) responses. This hypothesis was partially supported in the present study. Partners lower in attachment avoidance and anxiety were more likely to respond to the participant's capitalization in a more positive, supportive, activeconstructive manner. This supports the model of secure attachment described by Hazan and Shaver (1987) in that secure people are more able to accept and support their partners. Positive events may be viewed as threatening to the relationship (i.e., if one lost 50 pounds, might they now be more attractive to the opposite sex?) and the perception of this threat can lead to the selfprotecting mechanisms of hyperactivation (anxiety) or deactivation (avoidance) of the attachment system (Mikulincer \& Shaver, 2005). Therefore, insecure individuals might react to 
these positive event disclosures not out of pure, selfless excitement for their partners, but out of fear of what changes those positive events may bring. It may be that only secure individuals can truly feel pride and joy in their partner's accomplishments (Mikulincer \& Shaver, 2005).

In addition, results of this analysis also indicated that female partners were more likely to respond to the participant's capitalization in an active-constructive manner. Previous research has shown that women are more likely to express their emotions than are men (Brody \& Hall, 2000), and are generally better than men at savoring and maximizing their own positive events (Bryant, 1989). It may be that men are minimizing the impact of their positive events while sharing them with their female partners, and women are attempting to support the male participants by helping them to see the positive qualities of those events. Women may be reacting to their partner's events in the same way that they would likely respond to their own positive events - with overt enthusiasm. Women are also more likely to use backchannels when listening to others, which are verbal (i.e. saying "yeah") and nonverbal (i.e. nodding) cues aimed at empathizing with the speaker to maintain the conversation (Roger \& Nesshoever, 1987). In addition, women generally are more likely to serve as caregivers and to be more supportive towards others, and are often better at providing appropriate support to their partners when it is needed most (Neff \& Karney, 2005). In prior research, it has been suggested that women are better at providing emotionally charged, sensitive support with a person-centered (demonstrating their knowledge of the person in need while remaining non-judgmental) focus, so they may be reacting with higher levels of support due to their greater skills in this area (Kunkel \& Burleson, 1999; MacGeorge, Gillihan, Samter, \& Clark, 2003).

In addition to exploring how partner's attachment impacted the responses they gave participants, attachment was also used to predict how the participant perceived their partner's 
response to them when they shared a personal positive event. It was expected that participants lower in attachment avoidance and anxiety would report that their partners responded in a more active-constructive manner to their capitalization attempts. This hypothesis was partially supported, in that those lower in attachment anxiety reported that their partners were responding to them with more active-constructive responses. Again, this finding is clarified by past research on how highly anxious people react to positive emotions. Because they do not experience increases in positive mood (and may actually experience a worsening mood) in response to positive affect (Mikulincer \& Sheffi, 2000), anxious participants who receive positive feedback from partners may be unable to interpret that feedback as uniformly supportive and positive. Highly anxious individuals often have difficulty in reducing their attention to perceived threats, even when experiencing positive relational events (Shaver \& Mikulincer, 2008), which may cause them to consider more negative aspects of their positive events or their partners' reactions. Highly anxiously attached individuals also need to perceive that their partner is supportive in order to feel secure in the relationship and they are also more likely to interpret ambiguous (i.e. passive) feedback as threatening or non-supportive (Campbell et al., 2005). Finally, highly anxiously attached people sometimes have difficulty interpreting the cues they give people of romantic interest (Vorauer, Cameron, Holmes, \& Pearce, 2003), and thus, high attachment anxiety may be related to a more global difficulty with interpreting the responses of others. Therefore, it may be that only those low in attachment anxiety (as compared to those high in attachment anxiety) are able to accept their partners' positive feedback at face value, and feel supported when sharing positive events with partners.

Finally, it was expected that participants lower in attachment anxiety and avoidance (secure) would have a more accurate perception of their partner's response when compared to the 
response their partner reported. There was some support to suggest that those participants higher in attachment avoidance had the largest degree of discrepancy between their reports of the partner's behavior and the partner's self-reported behavior. However, the overall model was no longer significant when attachment security was included in the model. Finally, in testing whether secure individuals were more accurate or if participant's attachment avoidance or anxiety predicted negative perceptions of their partner's behavior, no significant results were found.

Even though the findings for attachment avoidance were somewhat weak, there are theoretical reasons behind why people higher in avoidance may be more discrepant when compared with their partners. People higher in attachment avoidance have a preference for emotional distance, and fear becoming dependent on their partners. Therefore, they often attempt to distance themselves from their partners and to regulate their insecurity and positive emotions on their own (Butner, Diamond, \& Hicks, 2007; Hazan \& Shaver, 1987). Specifically, individuals higher in attachment avoidance often fail to appropriately and outwardly express their positive emotions, which may make it more difficult for partners to determine how to react to the positive events they do share. They are less likely to use nonverbal expressions of interest and support (smiling, touching, and gazing) when engaging in discussions with their partners (Tucker \& Anders, 1998). In addition, those higher in attachment avoidance are also less likely to respond to changes in their partner's positive affect (Butner et al., 2007) so they may not notice when their partner responds in a positive way. Avoidant women are also less likely to report increases in their positive affect when sharing or hearing about positive events with their partners (Hicks \& Diamond, 2008). This may help to explain the pattern of findings in Hypothesis 4, in that highly avoidant people may be muting their own affect as well as being less 
attuned to their partner's feelings and responses than those lower in attachment avoidance. This may be why they are discrepant (but not necessarily more negative) from the responses their partners report; lack of affect or attention may cause them to report that their partner responded more or less negatively than the partner actually responded.

The presence of attachment differences in capitalization as well in (perceived) partner responses differs from the findings of Gable et al. (2006) and Hicks and Diamond (2008). However, there were several important differences between those studies and the present study. Specifically, in the Gable et al. study, attachment was found to marginally relate to partner responses, in that men scoring higher in avoidance were less likely to be rated by observers as responding in an active and constructive manner to their partners. However, participants in the Gable et al. study had already shared their positive event with their partner (most had discussed the event a great deal), and the capitalization measures were given before and during the positive event discussion, which may have primed participants to modify their reactions. The most important difference within the study by Gable and colleagues might be that they only used attachment to try to predict participant's behavior (from videotaped interactions) when responding to their partner's positive event sharing. In the present study, attachment relations were studied in a more comprehensive manner; in that they were assessed in relation to how often participants shared events and how they interpreted their partner's responses, as well as to the responses partners themselves reported. In other words, the present study involved more subjective measures that perhaps were tapping into how participants and partners actually felt during the disclosures. This is important because attachment insecurity is related to a discrepancy between expressed and felt emotion (Mikulincer \& Shaver, 2005) so it may be difficult to assess 
only from observations how insecure partners and participants are actually feeling during a conversation.

Hicks and Diamond (2008) found a relation between attachment avoidance and positive affect, in that more avoidantly attached women reported less of an increase in positive affect when hearing about and sharing positive events with their partners than did women scoring lower on avoidance. The biggest difference within the present study and the work by Hicks and Diamond may be the appropriateness of the outcome measure. The mutual regulation of positive affect, while important, may not be the best outcome measure in that it is not assessing how the participant feels about the relationship itself. Using relationship satisfaction as an outcome and measuring attachment differences in the frequency and quality of sharing and responding to positive events may be more sensitive to the types of fluctuations suggested by the attachment literature in the relational context. However, these studies (the present study, Gable et al., 2006, and Hicks \& Diamond, 2008), may best be viewed as complementary in that each study provided evidence the other did not due to methodological differences. Taken together, these studies might indicate that attachment is important for some aspects of positive event sharing, but that it might have a subtle or nuanced role in direct observable behaviors.

\section{Gender and Event Type}

In general, little support was found for the presence of gender and event type differences in these analyses. This is surprising because some evidence exists for the idea that women and men differ in their responses to positive events (Bryant, 1989; Bryant, Smart, \& King, 2005; Bryant \& Verhoff, 2007). In addition, previous research has demonstrated that events occurring in the presence of another person may be different than non-interpersonal events in some important ways (such as minimizing more with non-interpersonal events; see Gentzler et al., 
2010). However, in this study reactions to positive events were obtained shortly after the events occurred, and gender effects are less common in immediate reactions (Barrett \& Russell, 1998). In addition, the gender imbalance in the samples of participants (mostly women) and partners (mostly men) may help to explain why gender was largely non-significant in these analyses, despite its relation to positive event sharing and perception of responses in other studies. Finally, the few overall differences in interpersonal vs. non-interpersonal events may be related to the fact that, once the event is shared with a partner, the importance of that event for relationship satisfaction is still dependent on how the partner responds. For example, it may be just as detrimental to be ignored when one shares news of doing well on an exam as it is when one shares about going out with friends.

\section{Limitations}

One important limitation of this study was that no questions were asked about the means through which the events were first shared with their partners. Specifically, questions were not asked of participants as to whether they shared each event face-to-face or through some kind of mediated communication (such as email, telephone, or a social networking site). It is probable that responses given over text message or email may appear more passive (even if meant to express a great deal of excitement) than responses given in person. In addition, when positive events are shared face-to-face, a reaction is immediate. When positive events are shared through mediated means, participants may have to wait for a response. There may be important individual differences (i.e. attachment) that relate to how participants interpret this delay that affects their perceived support. Therefore, future research would be benefitted from a greater understanding of how sharing positive events across communication methods impacts the perception of received responses. 
In addition, no data were collected on the living situation of the participant and partner. Even though very few participants were married, it is possible that participants and partners living together (co-habitating) or in long-distance relationships may differ from couples living near one another but not in the same residence in the number of positive events they share with their partners, simply due to opportunity. In addition, those participants in long-distance relationships may share the majority of their positive events through mediated methods of communication, which may have effects on the way they perceive partner responses.

Also, the focus of the study was to understand positive event sharing within the context of romantic relationships, but each person within the couple completed separate study components. Therefore, no data was collected from partners on their events shared over the study period, and no information was collected from participants on how they typically respond to their partners. Romantic relationships are a bi-directional process, and therefore future research would benefit from a more comprehensive investigation of positive event sharing and responses within both members of the dyad.

There are also important limitations in that participants may have been aware of what the study was measuring, and changed their behavior accordingly. After completing measures in the initial lab visit about how their partners responded to their positive event sharing, and completing the first daily logs asking about partner reactions to shared events, it is possible that participants shared more events with partners or were more cognizant of their partners' reactions as a function of their participation. In addition, after completing one daily log participants would realize that they would be asked about positive events that occurred to them that day. Perhaps participants who did not experience any positive events that day chose not to log on to complete that days' log, as reporting no positive events was not an explicit option on the log. 
Finally, without any observational codes of the initial positive event sharing interactions between participant and partner, it is impossible to tell who is actually correct in their reported responses. This is especially important within the context of the final two hypotheses (investigating the relation between participant and partner report of the same event). For example, even though it appears that participants higher in attachment avoidance may be more discrepant from their partners in their report of the partners' response, it is difficult to tell if this is a factor inherent to the avoidant participants or if it is related to some interaction between participants and partners (perhaps avoidant participants all have insecure partners, who are also distorting the reports in some way). Some people also reported detailed descriptions of their partners' or their own reactions on the open-ended questions, while others reported very short responses with little detail. It is difficult to say if the partners' response really was curt, or if the participant just reported it as such. In addition, it is impossible to determine the flow of the conversation in which the positive event was shared without observational data. The use of observational data would be valuable in future studies to determine the proportion of supportive responses to everything that was said in the positive event discussion as well as to provide an unbiased view of the event disclosure and partner response. Future research would be strengthened by getting both subjective and objective measures of partner reports.

In conclusion, this study provides support for the idea that partner responses to positive event disclosures are more important for the health of relationships than simply the sharing of positive events or even feeling supported by a partner in general. In addition, results of this study suggest that attachment impacts how people respond to partners' positive event sharing, and also that attachment dimensions play an important role in how often people share positive events as well as how they perceive partner's responses to their sharing. Even though this study has 
important limitations, if replicated it could strengthen and expand the model of capitalization put forth by Gable and colleagues $(2004,2006)$ and could also help to further integrate attachment into this expanding line of research. 


\section{References}

Ainsworth, M., Blehar, M., Waters, E., \& Wall, S. (1978). Patterns of attachment: A psychological study of the strange situation. Oxford England: Lawrence Erlbaum.

Barrett, L. F., \& Russell, J. A. (1998). Independence and bipolarity in the structure of current affect. Journal of Personality and Social Psychology, 74, 967-984.

Bartholomew, K., \& Horowitz, L.M. (1991). Attachment styles among young adults: A test of a four-category model. Journal of Personality and Social Psychology, 61, 226-244.

Bartholomew, K., \& Shaver, P. (1998). Methods of assessing adult attachment: Do they converge?. Attachment theory and close relationships (pp. 25-45). New York, NY US: Guilford Press.

Bowlby, J. (1973). Attachment and loss: Vol. 2. Separation: Anxiety and anger. New York: Basic books.

Brennan, K., Clark, C., \& Shaver, P. (1998). Self-report measurement of adult attachment: An integrative overview. Attachment theory and close relationships (pp. 46-76). New York, NY US: Guilford Press.

Brody, L., \& Hall, J. (2000). Gender, emotion, and expression. In M. Lewis (Ed.), Handbook of emotions (pp. 338-349). New York, NY: Guilford Press.

Bryant, F. (1989). A four-factor model of perceived control: Avoiding, coping, obtaining, and savoring. Journal of Personality, 57(4), 773-797.

Bryant, F.B., Smart, C.M., King, S.P. (2005). Using the past to enhance the present: Boosting happiness through positive reminiscence. Journal of Happiness Studies, 6, 227-260.

Bryant, F.B., \& Verhoff, J. (2007). Savoring: A New Model of Positive Experience. Mahwah, NJ: Lawrence Erlbaum Associates. 
Butner, J., Diamond, L., \& Hicks, A. (2007). Attachment style and two forms of affect coregulation between romantic partners. Personal Relationships, 14(3), 431-455.

Campbell, L., Simpson, J., Boldry, J., \& Kashy, D. (2005). Perceptions of conflict and support in romantic relationships: The role of attachment anxiety. Journal of Personality and Social Psychology, 88(3), 510-531.

Carnelley, K., Israel, S., \& Brennan, K. (2007). The role of attachment in influencing reactions to manipulated feedback from romantic partners. European Journal of Social Psychology, 37(5), 968-986.

Cassidy, J. (1994). Emotion regulation: Influences of attachment relationships. Monographs of the Society for Research in Child Development, 59(2), 228-283.

Collins, N., \& Feeney, B. (2000). A safe haven: An attachment theory perspective on support seeking and caregiving in intimate relationships. Journal of Personality and Social Psychology, 78(6), 1053-1073.

Collins, N., \& Feeney, B. (2004). Working models of attachment shape perceptions of social support: Evidence from experimental and observational studies. Journal of Personality and Social Psychology, 87(3), 363-383.

Diamond, L., \& Fagundes, C. (2008). Developmental perspectives on links between attachment and affect regulation over the lifespan. Advances in child development and behavior (Vol 36) (pp. 83-134). San Diego, CA US: Elsevier Academic Press.

Eschenbeck, H., Kohlmann, C., \& Lohaus, A. (2007). Gender differences in coping strategies in children and adolescents. Journal of Individual Differences, 28(1), 18-26.

Fardis, M. (2008). Expression and regulation of emotions in romantic relationships. 
Feeney, J., \& Noller, P. (1990). Attachment style as a predictor of adult romantic relationships. Journal of Personality and Social Psychology, 58(2), 281-291.

Finkenauer, C., Engels, R., Branje, S., \& Meeus, W. (2004). Disclosure and relationship satisfaction in families. Journal of Marriage and Family, 66(1), 195-209.

Fisher, J. D., Nadler, A., \& Whitcher-Alagna, S. (1982). Recipient reactions to aid. Psychological Bulletin, 91, 27-54.

Fraley, R., \& Waller, N. (1998). Adult attachment patterns: A test of the typological model. Attachment theory and close relationships (pp. 77-114). New York, NY US: Guilford Press.

Fredrickson, B. (1998). What good are positive emotions?. Review of General Psychology, 2(3), 300-319.

Fredrickson, B. (2001). The role of positive emotions in positive psychology: The broadenand-build theory of positive emotions. American Psychologist, 56(3), 218-226.

Fredrickson, B. (2006). The Broaden-and-Build Theory of Positive Emotions. A life worth living: Contributions to positive psychology (pp. 85-103). New York, NY US: Oxford University Press.

Fredrickson, B., \& Branigan, C. (2005). Positive emotions broaden the scope of attention and thought-action repertoires. Cognition \& Emotion, 19(3), 313-332.

Fredrickson, B., \& Joiner, T. (2002). Positive emotions trigger upward spirals toward emotional well-being. Psychological Science, 13(2), 172-175.

Fujita, F., Diener, E., \& Sandvik, E. (1991). Gender differences in negative affect and wellbeing: The case for emotional intensity. Journal of Personality and Social Psychology, $61,427-434$. 
Furman, W. (1996). The measurement of children and adolescents' perceptions of friendships: Conceptual and methodological issues. In W. M. Bukowski, A. F. Newcomb, \& W. W. Hartup (Eds.), The company they keep: Friendships in childhood and adolescence. Cambridge, MA: Cambridge University Press.

Furman, W., \& Buhrmester, D. (1992). Age and sex differences in perceptions of networks of personal relationships. Child Development, 63(1), 103-115.

Gable, S., Reis, H., Impett, E., \& Asher, E. (2004). What do you do when things go right? The intrapersonal and interpersonal benefits of sharing positive events. Journal of Personality and Social Psychology, 87(2), 228-245.

Gable, S., Gonzaga, G., \& Strachman, A. (2006). Will you be there for me when things go right? Supportive responses to positive event disclosures. Journal of Personality and Social Psychology, 91(5), 904-917.

Gentzler, A., Kerns, K., \& Keener, E. (2010). Emotional reactions and regulatory responses to negative and positive events: Associations with attachment and gender. Motivation and Emotion, 34(1), 78-92.

Gottman, J. (1982). Emotional responsiveness in marital conversations. Journal of Communication, 32(3), 108-120.

Gottman, J., Coan, J., Carrere, S., \& Swanson, C. (1998). Predicting marital happiness and stability from newlywed interactions. Journal of Marriage \& the Family, 60(1), 5-22.

Gottman, J., \& Levenson, R. (1992). Marital processes predictive of later dissolution: Behavior, physiology, and health. Journal of Personality and Social Psychology, 63(2), 221-233.

Gottman, J., \& Levenson, R. (1999). How stable is marital interaction over time?. Family 
Process, 38(2), 159-165.

Hazan, C., \& Shaver, P.R. (1987). Romantic love conceptualized as an attachment process. Journal of Personality and Social Psychology, 52, 511-524.

Hendrick, S. (1981). Self-disclosure and marital satisfaction. Journal of Personality and Social Psychology, 40(6), 1150-1159.

Hendrick, S. (1988). A generic measure of relationship satisfaction. Journal of Marriage \& the Family, 50(1), 93-98.

Hendrick, S. S., Dicke, A., \& Hendrick, C. (1998). The relationship assessment scale. Journal of Social and Personal Relationships, 15(1), 137-142.

Hendrick, S., Hendrick, C., \& Adler, N. (1988). Romantic relationships: Love, satisfaction, and staying together. Journal of Personality and Social Psychology, 54(6), 980-988.

Hicks, A., \& Diamond, L. (2008). How was your day? Couples' affect when telling and hearing daily events. Personal Relationships, 15(2), 205-228.

Holladay, S., \& Kerns, K. (1999). Do age differences matter in close and casual friendships?: A comparison of age discrepant and age peer friendships. Communication Reports, 12(2), 101-114.

Kerr, S., Melley, A., Travea, L., \& Pole, M. (2003). The relationship of emotional expression and experience to adult attachment style. Individual Differences Research, 1(2), 108123.

Kunkel, A.W. \& Burleson, B. R. (1999). Assessing explanations for sex differences in emotional support: A test of the different cultures and skill specialization accounts. Human Communication Research, 25, 307-340. 
Langston, C. (1994). Capitalizing on and coping with daily-life events: Expressive responses to positive events. Journal of Personality and Social Psychology, 67(6), 1112-1125.

Lazarus, R.S., \& Folkman, S.F. (1984). Stress, Coping and Appraisal. New York: Springer Publishing Company.

Levenson, R., Carstensen, L., \& Gottman, J. (1994). Influence of age and gender on affect, physiology, and their interrelations: A study of long-term marriages. Journal of Personality and Social Psychology, 67(1), 56-68.

MacGeorge, E., Gillihan, S., Samter, W., \& Clark, R. (2003). Skill deficit or differential motivation? Testing alternative explanations for gender differences in the provision of emotional support. Communication Research, 30(3), 272-303.

Mikulincer, M., \& Shaver, P. (2005). Attachment theory and emotions in close relationships: Exploring the attachment-related dynamics of emotional reactions to relational events. Personal Relationships, 12(2), 149-168.

Mikulincer, M., \& Shaver, P. (2007). Attachment in adulthood: Structure, dynamics, and change. New York, NY US: Guilford Press.

Mikulincer, M., \& Sheffi, E. (2000). Adult attachment style and cognitive reactions to positive affect: A test of mental categorization and creative problem solving. Motivation and Emotion, 24(3), 149-174.

Morey, J., Keener, E., Gentzler, A. (2009). Coping in Response to Positive Events: Do Gender, Attachment, and Type of Event Matter? Poster presented at the World Congress on Positive Psychology, Philadelphia, PA.

Neff, L., \& Karney, B. (2005). Gender differences in social support: A question of skill or responsiveness?. Journal of Personality and Social Psychology, 88(1), 79-90. 
Pasupathi, M., Carstensen, L., Levenson, R., \& Gottman, J. (1999). Responsive listening in long- married couples: A psycholinguistic perspective. Journal of Nonverbal Behavior, 23(2), 173-193.

Reis, H., Smith, S., Carmichael, C., Caprariello, P., Tsai, F., Rodrigues, A., Maniaci, M. R. (2010). Are you happy for me? How sharing positive events with others provides personal and interpersonal benefits. Journal of Personality and Social Psychology, 99(2), 311-329.

Roger, D., \& Nesshoever, W. (1987). Individual differences in dyadic conversational strategies: A further study. British Journal of Social Psychology, 26(3), 247-255.

Shaver, P. R., \& Mikulincer, M. (2008). Adult attachment and cognitive and affective reactions to positive and negative events. Social and Personality Psychology Compass, 2(5), 18441865.

Simpson, J., Collins, W., Tran, S., \& Haydon, K. (2007). Attachment and the experience and expression of emotions in romantic relationships: A developmental perspective. Journal of Personality and Social Psychology, 92(2), 355-367.

Tabachnick, B.G. \& Fidell, L.S. (2007) Using Multivariate Statistics, $5^{\text {th }}$ edition. New York: Harper Collins.

Tsagarakis, M., Kafetsios, K., \& Stalikas, A. (2007). Reliability and validity of the Greek version of the revised experiences in close relationships measure of adult attachment. European Journal of Psychological Assessment, 23(1), 47-55.

Tucker, J., \& Anders, S. (1998). Adult attachment style and nonverbal closeness in dating couples. Journal of Nonverbal Behavior, 22(2), 109-124.

Tugade, M., \& Fredrickson, B. (2004). Resilient individuals use positive emotions to bounce 
back From negative emotional experiences. Journal of Personality and Social Psychology, 86(2), 320-333.

Tugade, M., Fredrickson, B., \& Barrett, L. (2004). Psychological resilience and positive emotional granularity: Examining the benefits of positive emotions on coping and health. Journal of Personality, 72(6), 1161-1190.

Vorauer, J., Cameron, J., Holmes, J., \& Pearce, D. (2003). Invisible overtures: Fears of rejection and the signal amplification bias. Journal of Personality and Social Psychology, 84(4), 793-812. 
Table 1

Data Collection Waves Across Time and Raters

\begin{tabular}{|c|c|c|}
\hline \multicolumn{3}{|c|}{ Collection Periods } \\
\hline Time 1 & One-week interval & Time 2 \\
\hline Participant & Participant & $\begin{array}{c}\text { Participant (completed at end of } \\
\text { last daily log; day 7) }\end{array}$ \\
\hline Informed consent & Daily logs (7 total) & General PRCA scale \\
\hline Demographics & $\begin{array}{l}\text { Open-ended questions } \\
\text { about the daily positive } \\
\text { event }\end{array}$ & RAS \\
\hline Email address for partner & $\begin{array}{l}\text { Event-specific PRCA } \\
\text { for every event shared }\end{array}$ & \\
\hline $\begin{array}{l}\text { General Perceived Responses to } \\
\text { Capitalization Attempts Scale } \\
\text { (PRCA) }\end{array}$ & & $\begin{array}{c}\text { Partner (completed after } \\
\text { participant finishes Time 2) }\end{array}$ \\
\hline $\begin{array}{l}\text { Experiences in Close Relationships } \\
\text { (ECR) Scale }\end{array}$ & & Informed consent \\
\hline $\begin{array}{l}\text { Relationship Assessment Scale } \\
\text { (RAS) }\end{array}$ & & Demographics \\
\hline \multirow[t]{4}{*}{$\begin{array}{l}\text { Network of Relationships } \\
\text { Inventory (NRI) }\end{array}$} & & $\begin{array}{l}\text { Open-ended questions about } \\
\text { response to event }\end{array}$ \\
\hline & & ECR scale \\
\hline & & RAS \\
\hline & & $\begin{array}{l}\text { Event-specific self-report PRCA } \\
\text { scale }\end{array}$ \\
\hline
\end{tabular}


Table 2

Descriptive Information for Major Variables, as well as Descriptives by Gender and Event Type

\begin{tabular}{|c|c|c|c|c|c|c|c|c|c|c|c|}
\hline \multirow[t]{3}{*}{ Scale } & & & & \multicolumn{4}{|c|}{ Participant gender } & \multicolumn{4}{|c|}{ Event type } \\
\hline & & & & \multicolumn{2}{|c|}{$\begin{array}{l}\text { Male } \\
\mathrm{N}=14\end{array}$} & \multicolumn{2}{|c|}{$\begin{array}{c}\text { Female } \\
\mathrm{N}=78\end{array}$} & \multicolumn{2}{|c|}{$\begin{array}{c}\text { Interpersonal } \\
\mathrm{N}=36\end{array}$} & \multicolumn{2}{|c|}{$\begin{array}{l}\text { Non-interpersonal } \\
\qquad N=56\end{array}$} \\
\hline & $M$ & $S D$ & Range & $M$ & $S D$ & $M$ & $S D$ & $M$ & $S D$ & $M$ & $S D$ \\
\hline \# of events reported & 7.22 & 1.42 & $5-17$ & 7.07 & .83 & 7.24 & 1.50 & 7.53 & 1.98 & 7.02 & .86 \\
\hline Reported vs. shared events & .85 & .20 & $.17-1.0$ & .76 & .27 & .86 & .19 & $.90^{*}$ & .14 & $.81 *$ & .23 \\
\hline General PRCA (participant) & -1.80 & 8.39 & $-34.0-12.0$ & -1.36 & 6.11 & -1.88 & 8.77 & -1.08 & 8.48 & -2.27 & 8.37 \\
\hline Event-specific PRCA (participant) & -.49 & 11.04 & $-37.0-13.0$ & -2.68 & 11.73 & -.10 & 10.95 & -1.47 & 13.37 & .14 & 9.33 \\
\hline Event-specific PRCA (partner) & -2.22 & 10.32 & $-29.0-12.0$ & $* .79$ & 8.19 & $*-2.76$ & 10.61 & -4.75 & 11.51 & -.59 & 9.22 \\
\hline Relationship satisfaction time 1 & 6.22 & .59 & $4.57-7.0$ & 6.21 & .40 & 6.23 & .62 & 6.23 & .56 & 6.22 & .61 \\
\hline
\end{tabular}




\begin{tabular}{|c|c|c|c|c|c|c|c|c|c|c|c|}
\hline \multirow[t]{3}{*}{ Scale } & & & & \multicolumn{4}{|c|}{ Participant gender } & \multicolumn{4}{|c|}{ Event type } \\
\hline & & & & \multicolumn{2}{|c|}{$\begin{array}{l}\text { Male } \\
\mathrm{N}=14\end{array}$} & \multicolumn{2}{|c|}{$\begin{array}{c}\text { Female } \\
\mathrm{N}=78\end{array}$} & \multicolumn{2}{|c|}{$\begin{array}{c}\text { Interpersonal } \\
\mathrm{N}=36\end{array}$} & \multicolumn{2}{|c|}{$\begin{array}{c}\text { Non-interpersonal } \\
\qquad N=56\end{array}$} \\
\hline & $M$ & $S D$ & Range & $M$ & $S D$ & $M$ & $S D$ & $M$ & $S D$ & $M$ & $S D$ \\
\hline Relationship satisfaction time 2 & 6.24 & .59 & $4.43-7.0$ & 6.20 & .64 & 6.25 & .58 & 6.24 & .55 & 6.24 & .61 \\
\hline Relationship satisfaction partner & 6.29 & .73 & $3.14-7.0$ & 6.16 & .70 & 6.32 & .74 & 6.21 & .84 & 6.35 & .65 \\
\hline Attachment anxiety (participant) & 2.24 & .86 & $1.0-5.17$ & 2.65 & .82 & 2.17 & .85 & 2.19 & .72 & 2.27 & .94 \\
\hline Avoidance (participant) & 1.40 & .23 & $1.0-2.25$ & 1.53 & .23 & 1.38 & .26 & 1.38 & .27 & 1.41 & .26 \\
\hline Anxiety (partner) & 1.46 & .32 & $1.0-2.36$ & 1.54 & .25 & 1.44 & .33 & 1.49 & .37 & 1.44 & .28 \\
\hline Avoidance (partner) & 1.36 & .28 & $1.0-2.24$ & 1.44 & .29 & 1.35 & .27 & 1.38 & .29 & 1.35 & .27 \\
\hline Social support & 4.25 & .43 & $3.07-5.0$ & 4.05 & .42 & 4.28 & .43 & 4.31 & .33 & 4.20 & .48 \\
\hline
\end{tabular}


Table 3

Correlations among the Perceived Responses to Capitalization Attempts (PRCA) Scales across Reporters and Measures of Major Constructs

\begin{tabular}{|c|c|c|c|c|c|}
\hline & \multirow{2}{*}{$\begin{array}{l}\text { General } \\
\text { General } \\
\text { PRCA }\end{array}$} & \multicolumn{4}{|c|}{ Specific } \\
\hline & & $\begin{array}{l}\text { PRCA Event- } \\
\text { specific } \\
\text { participant }\end{array}$ & $\begin{array}{l}\text { PRCA } \\
\text { Event- } \\
\text { specific } \\
\text { partner }\end{array}$ & $\begin{array}{l}\text { Open-ended } \\
\text { response: } \\
\text { participant }\end{array}$ & $\begin{array}{l}\text { Open-ended } \\
\text { response: } \\
\text { partner }\end{array}$ \\
\hline \multicolumn{6}{|l|}{ Raters } \\
\hline PRCA general (participant) & 1.0 & $.52 * *$ & $.31 *$ & .22 & .24 \\
\hline Event-specific (participant) & - & 1.0 & $.53 * *$ & $.53 * *$ & .23 \\
\hline Event-specific (partner) & - & - & 1.0 & $.34 *$ & $.40 * *$ \\
\hline $\begin{array}{l}\text { Open-ended response: } \\
\text { participant }\end{array}$ & - & - & - & 1.0 & -.15 \\
\hline \multicolumn{6}{|l|}{ Scales } \\
\hline $\begin{array}{l}\text { Satisfaction Time } 1 \\
\text { participant }\end{array}$ & $.34 *$ & .24 & $.47 * *$ & $.34^{*}$ & .17 \\
\hline $\begin{array}{l}\text { Satisfaction Time } 2 \\
\text { participant }\end{array}$ & .22 & $.38 * *$ & $.51 * *$ & $.33^{*}$ & .17 \\
\hline Satisfaction: Partner & .20 & $.27 *$ & $.36 * *$ & $.32 *$ & -.02 \\
\hline Anxiety (participant) & $-.54 * *$ & $-.43 * *$ & $-.29 *$ & $-.32 *$ & .00 \\
\hline Avoidance (participant) & $-.38 * *$ & $-.28 *$ & -.20 & $-.35^{*}$ & -.14 \\
\hline Anxiety (partner) & -.05 & -.13 & $-.38 * *$ & -.05 & -.06 \\
\hline Avoidance (partner) & -.27 & -.26 & $-.46^{* *}$ & -.01 & -.18 \\
\hline Social support & $.57 * *$ & $.40 * *$ & $.44 * *$ & $.32 *$ & $.32 *$ \\
\hline
\end{tabular}

\section{John H. ou=Acquisitions Department,

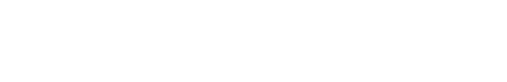

